\title{
Approaches to the Management of Hypertension in Resource-Limited Settings: Strategies to Overcome the Hypertension Crisis in the Post-COVID Era
}

This article was published in the following Dove Press journal: Integrated Blood Pressure Control

\author{
Jamario Skeete' \\ Kenneth Connell (iD ${ }^{2}$ \\ Pedro Ordunez $\mathbb{D}^{3}$ \\ Donald J DiPette ${ }^{4}$ \\ 'Division of Cardiology, Department of \\ Internal Medicine, Rush University \\ Medical Center, Chicago, IL, USA; \\ ${ }^{2}$ Faculty of Medical Sciences, University \\ of the West Indies, Cave Hill Campus, St. \\ Michael, Barbados; ${ }^{3}$ Department of Non- \\ Communicable Diseases and Mental \\ Health, Pan-American Health \\ Organization, Washington, DC, USA; \\ ${ }^{4}$ Department of Internal Medicine, \\ University of South Carolina School of \\ Medicine, University of South Carolina, \\ Columbia, SC, USA
}

\begin{abstract}
The COVID-19 pandemic has changed most aspects of everyday life in both the non-medical and medical settings. In the medical world, the pandemic has altered how healthcare is delivered and has necessitated an aggressive and new coordinated public health approach to limit its spread and reduce its disease burden and socioeconomic impact. This pandemic has resulted in a staggering morbidity and mortality and massive economic and physical hardships. Meanwhile, non-communicable diseases such as hypertension, diabetes mellitus, and cardiovascular disease in general continue to cause significant disease burden globally in the background. Though presently receiving less attention in the public eye than the COVID-19 pandemic, the hypertension crisis cannot be separated from the minds of healthcare providers, policymakers and the general public, as it continues to wreak havoc, particularly in vulnerable populations in resource limited settings. On this background, many of the strategies being employed to combat the COVID-19 pandemic can be used to reenergize and galvanize the fight against hypertension and hopefully bring the public health crisis associated with uncontrolled hypertension to an end.
\end{abstract}

Keywords: hypertension control, COVID-19 pandemic, resource-limited settings

\section{Introduction}

In 2020, through the Coronavirus (COVID-19) pandemic the world witnessed the devastating way disease can produce wide-scale death and suffering. ${ }^{1}$ During the pandemic, almost every person globally was affected either by the virus itself or through the concurrent vast social and economic hardships produced in its wake. ${ }^{2}$ In parallel, another global public health crisis has relentlessly continued in the background- the crisis of cardiovascular disease and its major risk factor, uncontrolled hypertension. ${ }^{3}$ Though more insidious in its onset when compared to COVID-19, the impact of cardiovascular disease is likewise, far reaching.

Though not a pandemic by strict definitions, cardiovascular disease is now reaching pandemic proportions and like the COVID-19 pandemic, calls for novel, aggressive and decisive public health action to "flatten" and "reverse" the curve of its current ascending trajectory. ${ }^{4-6}$ This is essential as, after decades of reductions in CVD premature mortality, a significant slowdown in this progress has been documented for the USA, and others high-income countries, ${ }^{7}$ a phenomena which is likely to be replicated in resource limited settings. To address this, every effort must be made to protect the gains already made and ultimately continue to reduce the cardiovascular disease burden. ${ }^{8}$
Correspondence: Jamario Skeete Division of Cardiology, Department of Internal Medicine, Rush University Medical Center, $1717 \mathrm{~W}$. Congress Parkway, Suite 317 Kellogg, Chicago, IL 60612 , USA

$\mathrm{Tel}+$ I 803-480-3275

Email Jamario_r_skeete@rush.edu
Integrated Blood Pressure Control 2020:13 |25-133 
Like the COVID-19 pandemic, understanding the risk factors for disease spread and poor outcomes is central to mounting an appropriate response. For cardiovascular disease, a major manageable risk factor fueling poor outcomes is uncontrolled hypertension. ${ }^{9,10}$ Beyond being an atherogenic factor for cardiovascular disease, hypertension is extremely prevalent and affects as many 1.4 billion individuals globally, which leads to a compounding of its impact. ${ }^{11}$ On the flip side, hypertension can be easily diagnosed, and in most cases, readily controlled. Therefore, with a deliberate and systematic approach on a global level, a large proportion of cardiovascular disease could be averted through the prevention and control of hypertension. $^{12}$

In this review, we explore the barriers to the control of hypertension and provide several strategies to overcome these barriers to increase the control rate of hypertension in both high income but more importantly in resourcelimited, LMICs. Where applicable, we will draw reference to key lessons we are learning through the global response to the COVID-19 pandemic, which shares some similarities to the cardiovascular disease and hypertension public health crises.

\section{The Story of Two Public Health Crises}

There are several key overlapping themes between the COVID-19 and the hypertension crises. For instance, both diseases call for early case detection, risk perception and determination of true disease prevalence. ${ }^{13,14}$ Both public health crises have highlighted health disparities across the globe and the need to address barriers to healthcare. ${ }^{15-17}$ Similarly, both crises have had large economic footprints and result in a significant strain on health-system resources. ${ }^{18,19}$ While inherent differences exist, it is important to learn from the aggressive approach to the control of COVID-19 and apply these strategies to the on-going challenges limiting the control of hypertension globally.

Though separate entities, it is difficult to divorce the fact the hypertension crisis has resulted in worsened outcomes during the on-going COVID-19 pandemic. Specifically, hypertension, which is widely prevalent, has been identified as a major risk factor for poor outcomes in patients who contract COVID-19. ${ }^{20}$ Many hypotheses have been postulated as to why this might be the case, including the fact that the COVID-19 virus utilizes the ACE receptor to facilitate uptake with theoretical heightened risk in persons whose hypertension is treated with ACE-I. However, to date, this has not been shown in retrospective studies to be a realized concern. ${ }^{21}$ Other factors such as the role of underlying endothelial dysfunction which frequently accompanies hypertension, may make persons vulnerable to more severe complications of COVID-19, which can also disrupt endothelial function. ${ }^{22}$ Unfortunately, currently, there is no conclusive mechanism has been identified for the association between hypertension and COVID-19. ${ }^{23}$

\section{Barriers to the Control of Hypertension in LMICs in the Wake of COVID-I 9}

Even before the COVID-19 pandemic, there were several barriers to the control of hypertension in resource limited settings (Table 1$)^{11}$

This has been compounded in the wake of the COVID-19 crisis which significantly disrupted healthcare delivery (Table 2). To address these emerging public health crises, barriers to success need to be identified and overcome. . $^{19,23,24}$

Of the factors noted, a major barrier limiting the control of hypertension in the pre-COVID era that is likely to persist in the post-COVID era is the limited access to healthcare in many LMICs. Using the four key hallmarks of accessible healthcare; geographic accessibility, financial affordability, availability, and acceptability, large populations in LMICs and even groups of population in high-income countries do not have accessible healthcare. ${ }^{24}$ Beyond this, when available, in many developing countries, the existing capacity to adequately manage and treat hypertension is lacking. ${ }^{25}$ This runs parallel to the poor access to diagnosis and treatment seen during the COVID-19 pandemic. ${ }^{26}$ Moving forward, deliberate attempts should be made to improve access to care.

Other significant barriers to the control of hypertension involve healthcare providers, and centers around the knowledge and perception about hypertension and the need for its aggressive management. Clinical/therapeutic inertia is increasingly becoming recognized as a major, if not the most important both, health system and provider barrier. These issues might be compounded by the current concern - and confusion - surrounding ACE-I and ARBs and outcomes in hypertension in the setting of the COVID-19 pandemic. Strategies should be employed to increase provider knowledge base through training and provision of evidence-based guidelines. 
Table I Barriers to the Successful Control of Hypertension in Resource-Limited Settings

\begin{tabular}{|c|c|c|}
\hline $\begin{array}{l}\text { Health System } \\
\text { Barriers }\end{array}$ & Provider Barriers & Patient Barriers \\
\hline $\begin{array}{l}\text { - Limited access to } \\
\text { healthcare and/or } \\
\text { - laboratory testing } \\
\text { Inadequate } \\
\text { resources to screen } \\
\text { for and manage } \\
\text { hypertension } \\
\text { - Lack of a reliable } \\
\text { supply of effective } \\
\text { and safe antihyper- } \\
\text { tensive medications } \\
\text { - Consumption } \\
\text { healthcare dollars to } \\
\text { treat hypertensive } \\
\text { complications and } \\
\text { other competing } \\
\text { diseases } \\
\text { - Lack of a system for } \\
\text { clinical monitoring } \\
\text { and performance } \\
\text { evaluation, including } \\
\text { a system in place to } \\
\text { address the clinical } \\
\text { inertia. }\end{array}$ & $\begin{array}{l}\text { - Limited applica- } \\
\text { tion and adher- } \\
\text { ence to clinical } \\
\text { guidelines } \\
\text { - Clinical/ } \\
\text { Therapeutic iner- } \\
\text { tia to initiate and/ } \\
\text { or intensify treat- } \\
\text { ment when } \\
\text { indicated } \\
\text { - Reluctance to } \\
\text { treat an asympto- } \\
\text { matic disease }\end{array}$ & $\begin{array}{l}\text { - Reduced health } \\
\text { literacy } \\
\text { - Limited access to } \\
\text { healthcare } \\
\text { services } \\
\text { - Lack of concern/ } \\
\text { urgency to con- } \\
\text { trol blood given } \\
\text { the lack of } \\
\text { symptoms } \\
\text { - Adoption of wes- } \\
\text { ternized lifestyles } \\
\text { - Fear of side } \\
\text { effects to antihy- } \\
\text { pertensive } \\
\text { medications } \\
\text { - Inability to afford } \\
\text { antihypertensive } \\
\text { medications }\end{array}$ \\
\hline
\end{tabular}

\section{Flattening the Curve: Reducing Complication Rates and Limiting Resource Consumption}

Through the COVID-19 pandemic, the importance of "flattening the curve" as a powerful strategy to reduce the rate of spread and reduce the rate of consumption of healthcare resources became a key public health message. This same strategy should be applied to hypertension given its high and increasing prevalence as well as its high complication rate. Central to this strategy is understanding how the disease and its complications occur and instituting the appropriate suppressive and mitigating methods.

The hypertension paradigm starts with the presence of risk factors and progresses to the development of complications. With a long, insidious course, often spanning decades, there are numerous opportunities for intervention in resource limited settings (Figure 1). To significantly improve hypertension control rates, a stepwise approach is paramount, addressing deficiencies at each step of the paradigm and hopefully to foster a paradigm shift.
Table 2 New Challenges to the Management of Hypertension in the Wake of COVID-19

\begin{tabular}{|c|c|c|}
\hline $\begin{array}{l}\text { Health System } \\
\text { Barriers }\end{array}$ & Provider Barriers & Patient Barriers \\
\hline $\begin{array}{l}\text { Diversion of } \\
\text { finances to fund } \\
\text { COVID-I9 } \\
\text { response } \\
\text { - Disruption of } \\
\text { medical supply } \\
\text { chains } \\
\text { - Cancellation of } \\
\text { clinics during local } \\
\text { lockdowns } \\
\text { - Social distancing } \\
\text { protocols limiting } \\
\text { access to care. } \\
\text { - Lack of a risk stra- } \\
\text { tification system } \\
\text { to identify the } \\
\text { need for care, } \\
\text { including the type, } \\
\text { frequency, and } \\
\text { level of complexity } \\
\text { and specialization } \\
\text { of care. }\end{array}$ & $\begin{array}{l}\text { - Misinformation } \\
\text { surrounding use of } \\
\text { ACE-I and ARBs } \\
\text { given fears of } \\
\text { worsening out- } \\
\text { comes with } \\
\text { COVID-19 } \\
\text { - Change in clinic } \\
\text { format which } \\
\text { requires provider } \\
\text { education }\end{array}$ & $\begin{array}{l}\text { - Fear to attend } \\
\text { clinics due to fear } \\
\text { of contracting } \\
\text { COVID-I9 } \\
\text { - Misinformation on } \\
\text { ACE-I/ARBs wor- } \\
\text { sening outcomes } \\
\text { - Job losses and } \\
\text { financial stresses } \\
\text { resulting in patient } \\
\text { rationing of medi- } \\
\text { cations and not fill- } \\
\text { ing prescriptions } \\
\text { - Heavier use of tele- } \\
\text { health and video } \\
\text { visits may limit } \\
\text { access to less tech } \\
\text { savvy patients } \\
\text { - Gaps in treatment } \\
\text { leading to missed } \\
\text { medications with } \\
\text { increased risk for } \\
\text { acute complica- } \\
\text { tions of uncon- } \\
\text { trolled } \\
\text { hypertension }\end{array}$ \\
\hline
\end{tabular}

\section{Step I - Address Risk Factors}

Within many LMICs, many risk factors promote and accelerate the natural history of hypertension. These factors include but are not limited to obesity, diabetes mellitus, high sodium consumption, tobacco reduction, and sedentary lifestyles. Other risk factors are also frequently present in LMICs, such as decreased health literacy, poor access to healthcare facilities, high levels of pollution and low birthweights. ${ }^{27}$

During the COVID-19 pandemic, early recognition of risk factors which facilitate infectivity and population spread, and disease severity such as close social contact, suboptimal hand hygiene and concomitant chronic noncommunicable diseases such as hypertension and diabetes resulted in the formulation of urgent strategies to address these risk factors. ${ }^{28}$ Such strategies were observed to markedly halt the increase in the rate of infection spread and ultimately to decrease those infected. ${ }^{29}$ The same must be done to alter the increasing prevalence (equivalent to "spread") of hypertension. 


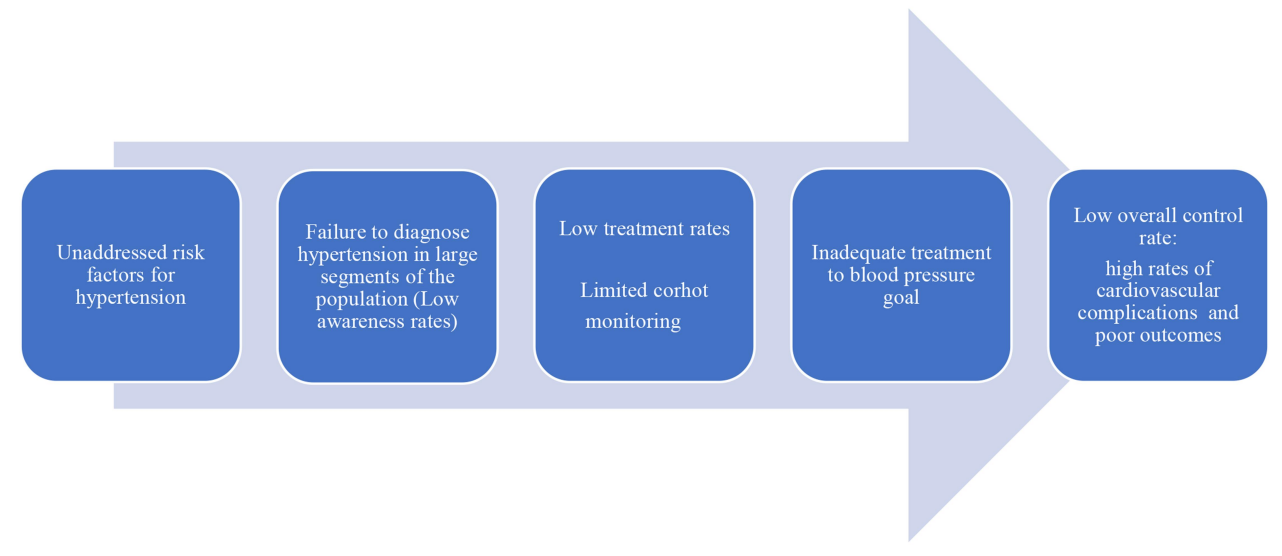

Figure I Paradigm of hypertension in resource-limited settings.

Through the implementation of strategies to mitigate hypertension risk factors starting at a national, public health level, significant potential exists to improve these risk factors. To date, there are several examples of strategies being used to mitigate these factors, some of which are highlighted in Table 3. Other strategies revolve around "best buys" defined as getting the most reduction in the risk factor for the least cost. While not without controversy and debate, a prime example of a "best buy" is to initiate or increase the tax on certain items, such as tobacco, refined sugar drinks, and alcohol. ${ }^{30}$

\section{Step 2 - Determine the True Disease Prevalence}

As was seen in the COVID-19 pandemic, one of the major factors responsible for the rapid spread of the disease was the inadequate identification of infected individuals (both asymptomatic and symptomatic) in this case through suboptimal testing rates. The same is true for hypertension, which has a long asymptomatic course and in resourcelimited settings, frequently goes undiagnosed.

In LMICs, the awareness of hypertension (the number of persons with hypertension who are aware of their condition) is generally low, estimated at $24 \%$, in parallel to low control rates. ${ }^{11}$ This contrasts to the $70-80 \%$ or greater awareness seen in some high-income countries. ${ }^{11}$ The disparity in this statistic between high income and LMICs is the product of several factors, which are potential sources/opportunities that can be addressed. The underpinning problem at play is the limited accessibility, acceptability, and utilization of health services. As most screening for hypertension traditionally occurs through interactions with the healthcaresystem, typically at clinics, limitations of the health-care system (especially in primary care health settings) significantly reduces the likelihood of diagnosis.

Addressing this barrier calls for a multifaceted approach in the post-COVID-19 era. Firstly, there is an increased need for government and policymakers to make available the resources necessary to build on the existing

Table 3 Current Factors and Potential Solutions to the Development of Hypertension

\begin{tabular}{|c|c|c|}
\hline Risk Factors & Potential Solutions & Success Stories \\
\hline $\begin{array}{l}\text { High sodium } \\
\text { consumption }\end{array}$ & $\begin{array}{l}\text { - Formulate national/ } \\
\text { regional campaigns } \\
\text { on sodium reduc- } \\
\text { tion particularly } \\
\text { content in prepared } \\
\text { foods } \\
\text { - Legislate need for } \\
\text { food labels } \\
\text { - Increase population } \\
\text { health literacy } \\
\text { - Set limits to sodium } \\
\text { content per serving } \\
\text { size }\end{array}$ & $\begin{array}{l}\text { Republic of South Africa } \\
\text { legislation on the } \\
\text { limitation of the upper } \\
\text { limit of sodium content } \\
\text { in processed foods. }{ }^{31} \\
\text { UK Food Standards } \\
\text { Agency's national salt } \\
\text { reduction campaign - } \\
\text { resulted in reduction in } \\
\text { the population's } \\
\text { average salt intake from } \\
9.5 \mathrm{~g} / \mathrm{d} \text { in } 2000-2001 \text { to } \\
8.6 \mathrm{~g} / \mathrm{d} \text { in } 2008^{32}\end{array}$ \\
\hline $\begin{array}{l}\text { Low levels of } \\
\text { physical activity } \\
\text { and limited } \\
\text { access to green } \\
\text { spaces }\end{array}$ & $\begin{array}{l}\text { - Increase access to } \\
\text { parks and green } \\
\text { spaces in urban } \\
\text { centers } \\
\text { - Improve public tran } \\
\text { sportation } \\
\text { - increased emphasis } \\
\text { on health promo- } \\
\text { tion activities } \\
\text { - Dissemination of } \\
\text { health promotion } \\
\text { content via text mes- } \\
\text { saging or social media }\end{array}$ & $\begin{array}{l}\text { Exercise promotion } \\
\text { campaigns in Latin- } \\
\text { America via text } \\
\text { messaging }^{33}\end{array}$ \\
\hline
\end{tabular}


healthcare infrastructure. In real terms, this means building both physical and human resource capacity as well as the use of several non-traditional hypertension screening methods. This model is successful in several LMICs through programs spearheaded by the Global Alliance for Chronic Disease. ${ }^{34}$ Similarly, utilizing a number of key community-based initiatives which seek to capture undiagnosed cases of hypertension is likely to see dividends (Table 4). These initiatives should be flexible enough to take into account social distancing practices which have now become the norm during the COVID-19 pandemic but could be relaxed once the pandemic is over.

\section{Channeling Screened Individuals to Definitive Care}

A key link in the chain and ultimate success of screening campaigns is the ability for persons who have been screened

Table 4 Methods to Improve Awareness of Hypertension

\begin{tabular}{|l|l|}
\hline Method & Implementation \\
\hline $\begin{array}{l}\text { Sensitize public through } \\
\text { campaigns" }\end{array}$ & $\begin{array}{l}\text { - Utilize social and tradition media } \\
\text { to provide information on the } \\
\text { importance of blood pressure } \\
\text { measurement }\end{array}$ \\
\hline $\begin{array}{l}\text { Increase access to affordable and } \\
\text { validated/accurate home blood } \\
\text { pressure measuring devices }\end{array}$ \\
\hline health workers & $\begin{array}{l}\text { Train and deploy individuals to } \\
\text { perform home/community-based } \\
\text { screening in remote or under - } \\
\text { accessed areas }\end{array}$ \\
\hline screening & $\begin{array}{l}\text { All individuals being seen for allied } \\
\text { healthcare professional visit, eg, } \\
\text { dentists, optometrists should have } \\
\text { blood pressure checked using } \\
\text { a standardized screening algorithm }\end{array}$ \\
\hline Barber shop screening & $\begin{array}{l}\text { Provide blood pressure checks in } \\
\text { the workplace } \\
\text { Incentivize employees to meet } \\
\text { blood pressure targets to reduce } \\
\text { overall cardiovascular risk }\end{array}$ \\
\hline Enhanced work-place & $\begin{array}{l}\text { Finding at risk populations - per- } \\
\text { forming screening and treatment } \\
\text { at non-traditional sites, eg, bar- } \\
\text { bershops and salons }\end{array}$ \\
\hline surening & $\begin{array}{l}\text { Placement of blood pressure mea- } \\
\text { eg pharmacies and supermarkets }\end{array}$ \\
\hline
\end{tabular}

and require definitive diagnosis, treatment, and control to obtain the care necessary. Building capacity such that screening programs are a reliable means to channel individuals into the healthcare system where a definitive diagnosis may be made and treatment initiated (Figure 2). An example of this "hub-and spoke" model was utilized in the Caribbean, conducted by the Healthy Caribbean Coalition, in which individuals in 5 countries were screened for hypertension by civil society organizations. ${ }^{35}$ These organizations interfaced with the healthcare system to channel persons with elevated blood pressures to receive a formal diagnosis of hypertension and treatment. This model of channeling patients into a treatment center is key in resource limited settings and also addresses the barrier of low follow up visit rates.

\section{Step 3 - Improving the Framework for the Treatment of Hypertension}

One area of significant difference between the COVID-19 pandemic and the global hypertension crisis/pandemic, is the presence of multiple proven pharmacologic and nonpharmacologic treatments for hypertension which have been shown to via evidenced-based medicine to improve clinical outcomes. As such, a third key action in resourcelimited settings is the appropriate simplification, standardization, and implementation of evidence-based pharmacologic treatment. To achieve this, a functional outcomes-based treatment framework must be put in place.

Traditionally, hypertension management was tailored at the level of the individual provider and patient. However, recently, novel programs have been designed and implanted to shift the diagnosis and treatment of hypertension to a public health/population-based level. Such a shift requires a large number of public and private stakeholders. ${ }^{36}$ This approach has been demonstrated to be extremely successful in both high-income settings and LMICs, as well as in private and/or public sectors. Two notable programs using this approach include the Kaiser Permanente Hypertension Program, one of the largest nonprofit healthcare systems in the United States, and the initial Standardized Hypertension Treatment Project piloted in Barbados ${ }^{36,37}$ The latter has now been expanded across Latin America and the Caribbean as the HEARTS in the Americas Program and the Global HEARTS Initiative under the leadership of the World Health Organization and its regional office for the Americas, the Pan-American Health Organization. A key component of these programs is the interaction between multiple 


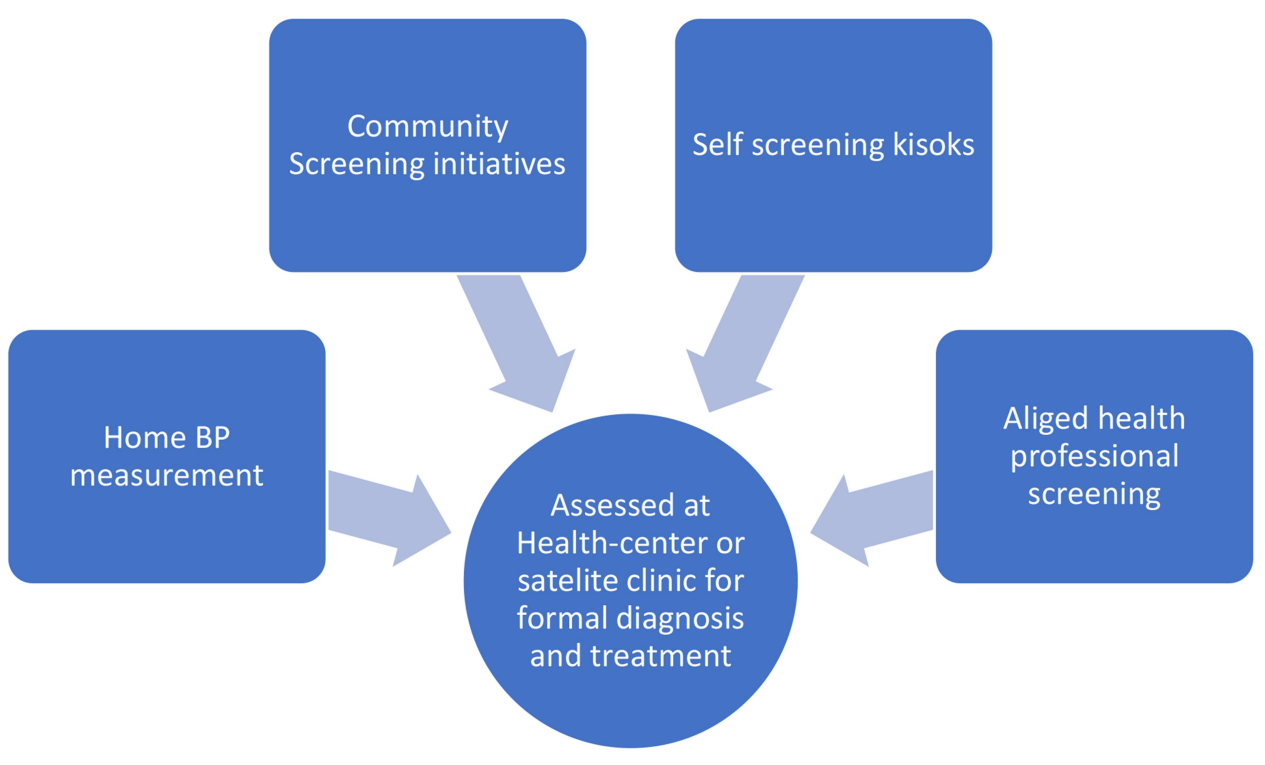

Figure 2 Model for referring persons with elevated blood pressures to a central health center for diagnosis and treatment.

stakeholders and interest groups, involving both governments and non-governmental organizations, such as Resolve to Save Lives, the World Hypertension League, and cardiovascular-related societies and associations, among others. ${ }^{38}$

HEARTS in the Americas has been implemented in 12 countries, 371 health centers which together cover approximately 6 million adults in the respective catchment areas. ${ }^{39}$ For instance, in a polyclinic in Matanzas, Cuba, following less than one year of the full implementation of the program, the prevalence of hypertension, proportion of the hypertensive population registered as having hypertension, proportion of those drug-treated who were controlled, and estimated population rate of control were $30 \%, 90 \%, 68 \%$, and $58 \%$, respectively. Based on these positive results, the program has been expanded to include another demonstration program initiated in a second region. In addition, preliminary efforts to disseminate and scale-up aspects of the program to the full Cuban population have started. ${ }^{40}$

Since blood pressure is the intermediate phenotype of the hypertensive individual and most treatment decisions according to all hypertension guidelines is based on the blood pressure level, the accurate measurement of the blood pressure is critical. Patient preparation and the proper blood pressure technique is essential. While it is intuitive that proper technique is essential, it is important to note that the blood pressure is rarely taken properly. Furthermore, the blood pressure measuring device utilized is also essential. Most guidelines now strongly recommend that the use of mercury/aneroid devices be replaced by automated, oscillometric devices both in the clinic and out of office settings. In addition, the use of a validated device is also essential. It is estimated, however, that only $20 \%$ or less of devices currently available are indeed validated. $^{41}$

In addition, the core of a population-based/public health approach to hypertension control is three-fold: 1) the presence of a small and simple anti-hypertensive medication formulary; 2) the development and implementation of a standardized and straightforward pharmacologic treatment algorithm; 3) the use in the algorithm of two medications either as two individual pills, or better yet in a single pill, fixed-dose combination in the initial treatment of the newly diagnosed hypertensive individual. Programs incorporating these attributes are especially suited for use in LMICs.

Presently, all recent hypertension guidelines recommend the use of any of three classes of antihypertensive medications in the initial treatment of hypertension: 1) thiazide and thiazide-like diuretics; 2) renin-angiotensinaldosterone system inhibitors, which is composed of two sub-classes: Angiotensin-converting enzyme inhibitors or Angiotensin receptor blockers; and 3) calcium channel blockers. ${ }^{42,43}$ A small and simple medication formulary would consist of incorporating a primary and secondary agent for select classes in each of these four groups of medications. 
The next critical step is to plan and implement a standardized and straightforward treatment algorithm. The adoption and uniform use of a treatment algorithm has been shown to significantly increase hypertension control rates. One major reason for this success is that the use of an algorithm directly addresses therapeutic/clinical inertia, mentioned above. While there are several attributes of a successful algorithm, a key attribute is that it needs to be primary care based and developed to address the patient "rule" and not the patient "exception" (ie, for $80 \%$ to $90 \%$ of the primary care hypertensive population). As such, while specialists are key stakeholders in the planning and implementation of the algorithm, the primary stakeholders are the primary care providers and staff and their involvement and leadership is key. Of course, lifestyle modification is a key complementary component of any pharmacologic treatment algorithm.

A further strong consideration in a population-based treatment approach is to utilize two anti-hypertensive agents together in the initial treatment of hypertension, and where possible as fixed-dose, single-pill combinations. ${ }^{44}$ There are several advantages of such a strategy including: the observation that most ( $70 \%$ to $80 \%$ of individuals) will need two agents eventually. Two agents selected from complementary classes yields a greater and a more rapid blood pressure reduction, uses lower doses of each agent, and if complementary classes are used may reduce the side effects of each agent. Additionally, this strategy affords a simpler regimen which improves patient adherence, reduces therapeutic or clinical inertia, lowers the blood pressure equally among diverse demographic groups (sex, age, race, ethnicity which is particularly relevant to the global treatment of hypertension in low resource settings). Beyond this, this approach may yield benefits of leading to fewer clinic visits which free up clinic capacity to address other disease states.

As mentioned above, there are now several organizations, both private and public, that have instituted a population-based, public health approach to hypertension. One private organization, Kaiser Permanente in California, US, started such an approach well over 10 years ago. They established a small anti-hypertensive formulary for the program and implemented a standardized, and straightforward pharmacologic treatment algorithm using two anti-hypertensive agents in the initial treatment step. ${ }^{37}$ They rapidly titrated the initial two agents together, as the blood pressure level dictated and a third agent was added further as needed to achieve hypertension control. Using this approach, over a 10-year period from 2003 to
2013, hypertension control rates increase dramatically from $44 \%$ to $90 \%$ and the $90 \%$ level has been maintained to date. In addition, a significant reduction in cardiovascular disease event rates were observed over this same time period. In the post-COVID-19 era, using this approach of streamlined treatment algorithms should be a main component of the systemic management of hypertension.

\section{Step 4- Enhancing Cohort Monitoring and Utilization of Tele-Health}

Drawing further comparisons to the initial response to the COVID-19 pandemic, the ability to track clinical outcomes in patients and performance evaluation in health centers is a key tool used to gauge the success of the counter strategies being employed. Though not needed to the level of a major infectious disease crisis, hypertension control in developing, low resource settings also requires the use of cohort monitoring and utilizing present as well as emerging technologies. In resource-limited settings, these can be developed and implemented in collaboration with other infrastructural advancements, such as telecommunication systems. Importantly, such programs and strategies can take advantage of the robust presence and penetrance of smartphones.

As was seen with the COVID-19 pandemic, the use of tele-health became a part of continued healthcare provision in the face of the need for social distancing. Such an approach for hypertension could see increased access to healthcare and improved outcomes should be maintained beyond the COVID-19 pandemic whenever clinically appropriate with the use of smartphone technology, patients and easily trained community healthcare workers can feed blood pressure values to the central clinic and in return, receive information on management changes, in the absence of a face to face physician/provider encounter. Beyond this, as seen in several settings, in both urban and rural communities, the establishment of virtual clinics in which persons with hypertension receive care by providers through telephone and video chat encounters. Building on this ability through the enhancement of the healthcare infrastructure is likely to be a worthwhile strategy going forward. Similarly, with the now widespread availability of affordable automated blood pressure monitors with Bluetooth transmission capabilities and increasing access to cellular phones and the internet, persons through centralized blood pressure checking sites, could 
independently, have their blood pressure monitored and communicated back to centralized clinics, leading to management changes as indicated.

\section{Conclusion}

The ongoing COVID-19 pandemic and the multiple lessons learned through this crisis, brings to the fore, many strategies that can be applied to the management of hypertension in low to middle-income countries. It also reminds us, of the need for a unified, multisector strategic approach, to not only identify the areas of deficiency to the existing management structure but more importantly, to develop meaningful solutions to likewise address this public health crisis. As such the formulation of programs that utilize a standardized and simplified approach to cardiovascular diseases management and cardiovascular risk factors, particularly the detection, treatment, and control of hypertension is likely to be essential going forward to address the increasing burden of hypertension, especially in resource-limited settings such as in LMICs.

\section{Disclaimer}

PO is a staff member of the Pan American Health Organization. The author alone is responsible for the views expressed in this publication, and they do not necessarily represent those of the Pan American Health Organization.

\section{Acknowledgment}

DJD is a Distinguished Health Sciences Professor at the University of South Carolina and the University of South Carolina School of Medicine, Columbia, South Carolina, United States of America.

\section{Disclosure}

There are no conflicts of interest to disclose by any of the authors, nor is there any relationship with industry.

\section{References}

1. Clark A, Jit M, Warren-Gash C, et al. Global, regional, and national estimates of the population at increased risk of severe COVID-19 due to underlying health conditions in 2020: a modelling study. Lancet Glob Health. 2020;8(8):e1003-e1017. doi:10.1016/S2214-109X(20)30264-3

2. Nicola M, Alsafi Z, Sohrabi C, et al. The socio-economic implications of the coronavirus pandemic (COVID-19): a review. Int J Surg. 2020;78:185-193. doi:10.1016/j.ijsu.2020.04.018

3. Cooper RS, Kaufman JS, Bovet P. Global burden of disease attributable to hypertension. JAMA. 2017;317(19):2017-2018. doi:10.1001/ jama.2017.4213

4. McDermott MM. The international pandemic of chronic cardiovascular disease. JAMA. 2007;297(11):1253-1255. doi:10.1001/jama.297.11.1253

5. Anand S. A commitment to curbing the pandemic of cardiovascular disease. Lancet. 2000;356(9226):347. doi:10.1016/S0140-6736(05)73636-9
6. Campbell NRC, Schutte AE, Varghese CV, et al. São Paulo call to action for the prevention and control of high blood pressure: 2020. J Clin Hypertens. 2019;21(12):1744-1752. doi:10.1111/jch.13741

7. Lopez AD, Adair T. Is the long-term decline in cardiovascular-disease mortality in high-income countries over? Evidence from national vital statistics. Int J Epidemiol. 2019;48 (6):1815-1823. doi:10.1093/ije/dyz143

8. Ortendahl JD, Diamant AL, Toth PP, Cherepanov D, Harmon AL, Broder MS. Protecting the gains: what changes are needed to prevent a reversal of the downward cardiovascular disease mortality trend? Clin Cardiol. 2019;42(1):47-55. doi:10.1002/clc.23097

9. Fuchs FD, Whelton PK. High blood pressure and cardiovascular disease. Hypertens (Dallas, Tex 1979). 2020;75(2):285-292. doi:10.1161/HYPERTENSIONAHA.119.14240

10. Kjeldsen SE. Hypertension and cardiovascular risk: general aspects. Pharmacol Res. 2018;129:95-99. doi:10.1016/j.phrs.2017.11.003

11. Mills KT, Bundy JD, Kelly TN, et al. Global disparities of hypertension prevalence and control - global disparities of hypertension prevalence and control a systematic analysis of population-based studies from 90 countries. Circulation. 2016;134(6):441-450. doi:10.1161/ CIRCULATIONAHA.115.018912

12. Joseph P, Leong D, McKee M, et al. Reducing the global burden of cardiovascular disease, part 1. Circ Res. 2017;121(6):677-694. doi:10.1161/CIRCRESAHA.117.308903

13. Zhai P, Ding Y, Wu X, Long J, Zhong Y, Li Y. The epidemiology, diagnosis and treatment of COVID-19. Int J Antimicrob Agents. 2020;55(5):105955. doi:10.1016/j.ijantimicag.2020.105955

14. Lackland DT. High blood pressure: a lifetime issue. Hypertension. 2009;54 (3):457-458. doi:10.1161/HYPERTENSIONAHA.109.135541

15. Ferdinand KC, Nasser SA. Understanding the importance of race/ ethnicity in the care of the hypertensive patient. Curr Hypertens Rep. 2015;17(3):15. doi:10.1007/s11906-014-0526-9

16. Webb Hooper M, Nápoles AM, Pérez-Stable EJ. COVID-19 and racial/ethnic disparities. JAMA. 2020;323(24):2466-2467. doi:10.1001/jama.2020.8598

17. Yancy CW. COVID-19 and African Americans. JAMA. 2020;323 (19):1891-1892. doi:10.1001/jama.2020.6548

18. Forouzanfar MH, Liu P, Roth GA, et al. Global burden of hypertension and systolic blood pressure of at least 110 to $115 \mathrm{~mm} \mathrm{Hg}$, 1990-2015. JAMA. 2017;317(2):165. doi:10.1001/jama.2016.19043

19. Roberton T, Carter ED, Chou VB, et al. Early estimates of the indirect effects of the COVID-19 pandemic on maternal and child mortality in low-income and middle-income countries: a modelling study. Lancet Glob Health. 2020;8(7):e901-e908. doi:10.1016/ S2214-109X(20)30229-1

20. Guan W, Ni Z, Hu Y, et al. Clinical characteristics of coronavirus disease 2019 in China. N Engl J Med. 2020;382(18):1708-1720. doi:10.1056/NEJMoa2002032

21. Reynolds HR, Adhikari S, Pulgarin C, et al. Renin-angiotensinaldosterone system inhibitors and risk of Covid-19. $N$ Engl J Med. 2020;382(25):2441-2448. doi:10.1056/NEJMoa2008975

22. Sardu C, Gambardella J, Morelli MB, Wang X, Marfella R, Santulli G. Hypertension, thrombosis, kidney failure, and diabetes: is COVID-19 an endothelial disease? A comprehensive evaluation of clinical and basic evidence. J Clin Med. 2020;9(5):1417. doi:10.3390/jcm9051417

23. COVID-19 and hypertension: what we know and don't know American College of Cardiology. Available from: https://www.acc. org/latest-in-cardiology/articles/2020/07/06/08/15/covid-19-andhypertension. Accessed July 12, 2020.

24. Peters DH, Garg A, Bloom G, Walker DG, Brieger WR, Hafizur Rahman M. Poverty and access to health care in developing countries. Ann N Y Acad Sci. 2008;1136(1):161-171. doi:10.1196/annals.1425.011

25. Skeete J, Connell K, Ordunez P, DiPette DJ. The American College of Cardiology/American Heart Association 2017 hypertension guideline: implications for incorporation in Latin America, the Caribbean, and other resource-limited settings. J Clin Hypertens. 2018;20 (9):1342-1349. doi:10.1111/jch.13343 
26. Kavanagh MM, Erondu NA, Tomori O, et al. Access to lifesaving medical resources for African countries: COVID-19 testing and response, ethics, and politics. Lancet. 2020;395(10238):1735-1738. doi:10.1016/S0140-6736(20)31093-X

27. Ibrahim MM, Damasceno A. Hypertension in developing countries. Lancet. 2012;380(9841):611-619. doi:10.1016/S0140-6736(12)60861-7

28. Wang J, Li Z, Cheng X, et al. Epidemiologic characteristics, transmission chain, and risk factors of severe infection of COVID-19 in Tianjin, a Representative Municipality City of China. Front Public Health. 2020;8:198. doi:10.3389/fpubh.2020.00198

29. Desai AN, Patel P. Stopping the spread of COVID-19. JAMA. 2020;323(15):1516. doi:10.1001/jama.2020.4269

30. Bader P, Boisclair D, Ferrence R. Effects of tobacco taxation and pricing on smoking behavior in high risk populations: a knowledge synthesis. Int J Environ Res Public Health. 2011;8(11):4118-4139. doi:10.3390/ijerph8114118

31. Peters SAE, Dunford E, Ware LJ, et al. The sodium content of processed foods in South Africa during the introduction of mandatory sodium limits. Nutrients. 2017;9(4):404. doi:10.3390/nu9040404

32. Wyness LA, Butriss JL, Stanner SA. Reducing the population's sodium intake: the UK Food Standards Agency's salt reduction programme. Public Health Nutr. 2012;15(2):254-261. doi:10.1017/ S1368980011000966

33. Heath GW, Parra DC, Sarmiento OL, et al. Evidence-based intervention in physical activity: lessons from around the world. Lancet. 2012;380(9838):272-281. doi:10.1016/S0140-6736(12)60816-2

34. Vedanthan R, Bernabe-Ortiz A, Herasme OI, et al. Innovative approaches to hypertension control in low- and middle-income countries. Cardiol Clin. 2017;35(1):99-115. doi:10.1016/j.ccl.2016.08.010

35. Patel P, Ordunez P, Connell K, Lackland D, DiPette D. Standardized hypertension management to reduce cardiovascular disease morbidity and mortality worldwide. South Med J. 2018;111(3):133-136. doi:10.14423/SMJ.0000000000000776

36. Patel P, Ordunez P, DiPette D, et al. Improved blood pressure control to reduce cardiovascular disease morbidity and mortality: the standardized hypertension treatment and prevention project. J Clin Hypertens (Greenwich). 2016;(Cdc):1-11. doi:10.1111/jch.12861
37. Jaffe MG, Lee GA, Young JD, Sidney S, Go AS. Improved blood pressure control associated with a large-scale hypertension program. JAMA. 2013;310(7):699. doi:10.1001/jama.2013.108769

38. Frieden TR, Bloomberg MR. Saving an additional 100 million lives. Lancet (London, England). 2018;391(10121):709-712. doi:10.1016/ S0140-6736(17)32443-1

39. HEARTS in the Americas - PAHO/WHO | Pan American Health Organization. Available from: https://www.paho.org/en/heartsamericas. Accessed April 27, 2020.

40. Valdés González Y, Campbell NRC, Pons Barrera E, et al. Implementation of a community-based hypertension control program in Matanzas, Cuba. J Clin Hypertens. 2020;22(2):142-149. doi:10.1111/jch.13814

41. Sharman JE, O'Brien E, Alpert B, et al. Lancet Commission on Hypertension group position statement on the global improvement of accuracy standards for devices that measure blood pressure. $J$ Hypertens. 2020;38(1):21-29. doi:10.1097/HJH.000000000000 2246

42. Whelton PK, Carey RM, Aronow WS, et al. 2017 ACC/AHA/AAPA/ $\mathrm{ABC} / \mathrm{ACPM} / \mathrm{AGS} / \mathrm{APhA} / \mathrm{ASH} / \mathrm{ASPC}$ NMA/PCNA guideline for the prevention, detection, evaluation, and management of high blood pressure in adults. J Am Coll Cardiol. 2018;71(19):e127 LP-e248. doi:10.1016/j.jacc.2017.11.006

43. Williams B, Mancia G, Spiering W, et al. 2018 ESC/ESH guidelines for the management of arterial hypertension: the task force for the management of arterial hypertension of the European Society of Cardiology (ESC) and the European Society of Hypertension (ESH). Eur Heart J. 2018;39(33):3021-3104. doi:10.1093/eurheartj/ ehy339

44. DiPette DJ, Skeete J, Ridley E, et al. Fixed-dose combination pharmacologic therapy to improve hypertension control worldwide: clinical perspective and policy implications. J Clin Hypertens. 2019. doi:10.1111/jch.13426
Integrated Blood Pressure Control

\section{Publish your work in this journal}

Integrated Blood Pressure Control is an international, peer-reviewed open-access journal focusing on the integrated approach to managing hypertension and risk reduction. Treating the patient and comorbidities together with diet and lifestyle modification and optimizing healthcare resources through a multidisciplinary team approach constitute key features of the journal. This journal is indexed on
American Chemical Society's Chemical Abstracts Service (CAS) The manuscript management system is completely online and includes a very quick and fair peer-review system, which is all easy to use. Visit http://www.dovepress.com/testimonials.php to read real quotes from published authors. 